\title{
Propagação por estacas de rizoma de Aspilia montevidensis (Spreng.) Kuntze
}

\section{Propagation by cuttings of the rhizome of Aspilia montevidensis (Spreng.) Kuntze}

\author{
Angeline Martini ${ }^{*}$; Daniela Biondi²; Camila Maria Natal ${ }^{3}$
}

\section{Resumo}

\begin{abstract}
A indicação do uso de espécies nativas no paisagístico tem se tornado a cada dia mais freqüente, porém encontrá-las no mercado ainda não é tarefa fácil. Um dos motivos para isso é a dificuldade na produção, que se inicia nos processos de propagação. Métodos eficazes de propagação de Aspilia montevidensis ainda não são conhecidos. Desta forma o objetivo desse trabalho foi realizar propagação vegetativa por estacas de rizoma de Aspilia montevidensis em diferentes estações do ano. Testaram-se dois tratamentos em cada estação: $T_{1}$ - secção apical do rizoma e $T_{2}-$ secção basal do rizoma, com três repetições de nove secções cada na primavera e verão e três repetições de dez secções cada no outono e inverno. As variáveis analisadas foram: percentagem de estacas enraizadas, vivas e mortas; número de raízes por estaca; número e comprimento das brotações em cada estaca. A análise estatística foi realizada pelo teste SNK a $95 \%$ de probabilidade. Houve diferença significativa entre os tratamentos para a percentagem de estacas vivas no período de verão, e no período de outono para a percentagem de estacas enraizadas $\left(\mathrm{T}_{1}=30,7 \%\right.$ e $\left.\mathrm{T}_{2}=0 \%\right)$, vivas e o número de raízes. Nos demais tratamentos e estações do ano não se verificaram diferenças estatísticas, embora a maior taxa de enraizamento tenha sido encontrada no verão (T1 $=73,6 \%$ e T2 $=38,15 \%$ ). Conclui-se que a estação do ano é um fator que influência na propagação vegetativa, por estacas de rizomas apicais de Aspilia montevidensis.
\end{abstract}

Palavras-chave: Enraizamento, ornamental, espécie nativa, mal-me-quer-do-campo, estepe, floricultura

\begin{abstract}
The indication for use of native species in the landscape has become increasingly more frequent, but find them on the market still is not easy. One reason for this is the difficulty in production, which begins in the processes of propagation. Effective methods of spreading Aspilia montevidensis are not yet known. Thus the objective of this study was to vegetative propagation by cuttings of the rhizome of Aspilia montevidensis in different seasons. Two treatments were tested in each season: T1 - section of the tip of the rhizome and T2- section of the base of the rhizome, with three repetitions each of nine sections in the spring and summer and three replicates of ten sections each fal and winter. The variables were: percentage of rooted cuttings, dead and living, number of roots per cutting, number and length of shoots in each stake. Statistical analysis was performed by the SNK test at $95 \%$ probability. There were significant differences between treatments for the percentage of live cuttings in summer and during autumn for the percentage of rooted cuttings $\left(\mathrm{T}_{1}=30.7 \%\right.$ and $\left.\mathrm{T}_{2}=0 \%\right)$, living and the number of roots. In the other treatments and stations there were no statistical differences, although the highest rate of rooting was found in summer $\left(\mathrm{T}_{1}=73.6 \%\right.$ and $\left.\mathrm{T}_{2}=38.15 \%\right)$. We conclude that the season is a factor that influences the propagation by cuttings of rhizomes of Aspilia montevidensis.
\end{abstract}

Key words: Roots, ornamental, native species, yellow calendula, steppe, floriculture

\footnotetext{
${ }^{1}$ Enga Florestal, Mestranda em Engenharia Florestal da Universidade Federal do Paraná, UFPR, Curitiba, PR. E-mail: martini. angeline@gmail.com

${ }^{2}$ Eng $^{\mathrm{a}}$ Florestal, Prof ${ }^{\mathrm{a}}$ Dr $^{\mathrm{a}}$ Associada II, Dept ${ }^{\mathrm{o}}$ de Ciências Florestais, UFPR, Curitiba, PR. Bolsista de Produtividade do CNPq. E-mail: dbiondi@ufpr.br

${ }^{3}$ Eng ${ }^{\text {a }}$ Florestal, UFPR, Curitiba, PR. E-mail: mila_natal@yahoo.com.br

* Autor para correspondência
} 
As espécies exóticas dominam o mercado brasileiro de plantas ornamentais. Isto ocorre principalmente devido à falta de informações, pesquisas e divulgação sobre o potencial das espécies nativas. Conforme Biondi e Leal (2006), o elenco de espécies nativas comercializadas é pouco representativo diante da diversidade existente. No paisagismo, desde a época do Brasil Colonial, houve uma substituição das espécies nativas pelas exóticas, devido à falta de informações para utilização de espécies nacionais em projetos paisagísticos. Muitas vezes, o valor das plantas nativas ornamentais só é reconhecido quando elas são estudadas e melhoradas por outros países.

Existe uma infinidade de espécies herbáceas com potencial para serem incluídas em práticas de ornamentação e paisagismo, mas que, talvez por razões culturais ou por falta de uma visão mais ampla sobre novas e infinitas possibilidades, ervas nativas raramente são associadas, lembradas ou reconhecidas como plantas que podem ser cultivadas e apreciadas pelos brasileiros (BARROSO, 2006).

Heiden, Barbieri e Stumpf (2006) afirmam que a inserção de plantas nativas com potencial ornamental na cadeia produtiva e sua disponibilização para a comercialização representam um diferencial em um mercado altamente competitivo, ávido por novidades e com tendência a tornar-se cada vez mais inclinado a produtos considerados de impacto ambiental reduzido.

O ecossistema de Campos cobriu a cidade de Curitiba e arredores, que atualmente, porém, estão submetidos a uma densa pastagem, apresentando por isso uma vegetação profundamente alterada. Os Campos apresentam aspecto fisionômico típico com a predominância da cobertura herbácea (KLEIN; HATSCHBACH, 1962). E assim, como em outras formações vegetais, tais como cerrado, caatinga e savana, as plantas acabaram por desenvolver órgãos especializados em reserva, seja de água ou nutrientes, para viabilizarem sua própria sobrevivência.
A ocorrência de sistemas subterrâneos gemíferos está estritamente relacionada com a sobrevivência de espécies em condições desfavoráveis do ambiente, favorecendo a regeneração dos ramos aéreos e/ou a propagação vegetativa das plantas (HAYASHI, 2003). A propagação vegetativa por órgãos subterrâneos espessados é de grande importância na natureza, visto que muitas das espécies que os possuem não produzem sementes ou as produzem em pequena quantidade (CARVALHO, 1991).

Uma das espécies freqüentemente encontrada nas áreas de Campos antropizada e que apresenta um grande potencial ornamental é Aspilia montevidensis (Spreng.) Kuntze. Espécie herbácea, perene, da família Asteraceae, conhecida popularmente como Mal-me-quer do campo, que apresenta inflorescência disposta na forma de capítulos, na coloração amarela (TAKEDA; FARAGO, 2001). O potencial ornamental desta espécie ocorre tanto devido à beleza das flores como pelo longo período de floração, quase o ano inteiro (LEAL et al., 2004). No paisagismo, pode ser utilizada como planta de forração em canteiros homogêneos a pleno sol (BIONDI; LEAL; WENDLING, 2007). Os mesmos autores ao testarem a propagação de $A$. montevidensis por sementes e estacas caulinares, constataram que a espécie apresenta difícil enraizamento, além de baixa percentagem de germinação.

Um dos fatores freqüentemente esquecido quando se avalia a propagação vegetativa se refere à influência das estações do ano. No entanto, segundo Browse (1998), existem flutuações na capacidade das estacas de raízes para a produção de gomos, sendo inútil executar trabalhos de propagação quando a resposta por parte da planta se encontra impedida devido influências adversas da estação do ano em curso. Portanto, torna-se essencial saber se a planta destinada a fornecer as estacas tem respostas diferentes conforme a época do ano e, se tal efeito ocorrer, qual é a melhor época para a obtenção desses órgãos de propagação. 
Neste contexto, o objetivo deste trabalho foi realizar a propagação vegetativa de Aspilia montevidensis em diferentes estações do ano por meio de estacas de rizomas.

As matrizes de Aspilia montevidensis (Spreng.) Kuntze foram coletadas em área localizada no Campus III da Universidade Federal do Paraná UFPR (Jardim Botânico), na cidade de CuritibaPR, situada a $25^{\circ} 25^{\prime}$ de latitude Sul e $49^{\circ} 16^{\prime}$ de longitude Oeste, a uma altitude de $908 \mathrm{~m}$ sobre o nível do mar. Segundo classificação de Köppen, a área apresenta clima do tipo $\mathrm{Cfb}$, temperado (ou subtropical) úmido, mesotérmico, sem estação seca, com verões frescos e invernos com geadas freqüentes e ocasionais precipitações de neve. As médias de temperatura são de $21,1{ }^{\circ} \mathrm{C}$, no verão e $14,77^{\circ} \mathrm{C}$, no inverno. A precipitação média anual é de 1385,35 mm, e a umidade média relativa do ar é de 79,3 (IPPUC, 2010). A vegetação da área de estudo, antes da interferência antrópica, era constituída pela vegetação Estepe Gramíneo-Lenhosa.

Ao final de cada estação do ano (fevereiro, junho, agosto, dezembro) em 2008, os rizomas advindos das matrizes foram escavados com auxílio de pá e enxada, seguidos por lavagem em água corrente e segmentados em secções de rizoma (estacas com 6 $\mathrm{cm}$ de comprimento). $\mathrm{O}$ experimento foi montado em delineamento inteiramente casualizado, em cada estação do ano, onde os tratamentos testados foram: secção apical do rizoma - $T_{1}$ e secção basal do rizoma $-\mathrm{T}_{2}$.

A quantidade de secções de rizoma em cada estação do ano variou devido à disponibilidade de material no campo. Na primavera e verão foram realizadas três repetições de nove secções em cada tratamento e no outono e inverno fora três repetições de dez secções cada.
Antes do plantio das estacas no leito de enraizamento foi aplicado tratamento fitossanitário no material de propagação, com hipoclorito de sódio a $0,5 \%$ durante dez minutos, com posterior lavagem em água corrente por cinco minutos (FERRIANI et al., 2006). As estacas foram plantadas verticalmente e o substrato utilizado foi vermiculita. O ambiente de enraizamento foi em viveiro aberto lateralmente, coberto com sombrite $50 \%$ e as bandejas de plástico branco $(50 \mathrm{~cm} \times 35 \mathrm{~cm} 10 \mathrm{~cm})$ foram periodicamente umedecidas. As variáveis analisadas foram: percentagem de estacas enraizadas (EE), não enraizados, mas vivas (EV) e mortas (EM); número de raízes por estaca (NRE) e comprimento da raiz por estaca (CMR); número (NB) e comprimento das brotações em cada estaca (CB).

A avaliação ocorreu 30 dias após o plantio e os dados foram submetidos à análise de variância. Inicialmente as variâncias dos tratamentos foram avaliadas quanto a sua homogeneidade pelo teste de Bartlett. As médias foram testadas por meio do teste $\mathrm{F}$ e comparadas pelo teste SNK a $5 \%$ de significância

Para as variáveis comprimento da raiz por estaca (CMR), percentagem de estacas mortas (EM), número de brotações (NB) e comprimento das brotações (CB) não foi encontrada interação significativa $(p>0,05)$ entre a secção apical do rizoma e secção basal do rizoma em nenhuma estação do ano. Foi encontrada diferença significativa quanto à porcentagem de estacas vivas na estação do verão e outono. Para as variáveis percentagem de estacas enraizadas (EE) e número de raízes por estaca (NRE) houve diferença estatística entre os tratamentos apenas na estação do outono. A análise estatística dos tratamentos utilizados em cada estação do ano pode ser observada na Tabela 1. 


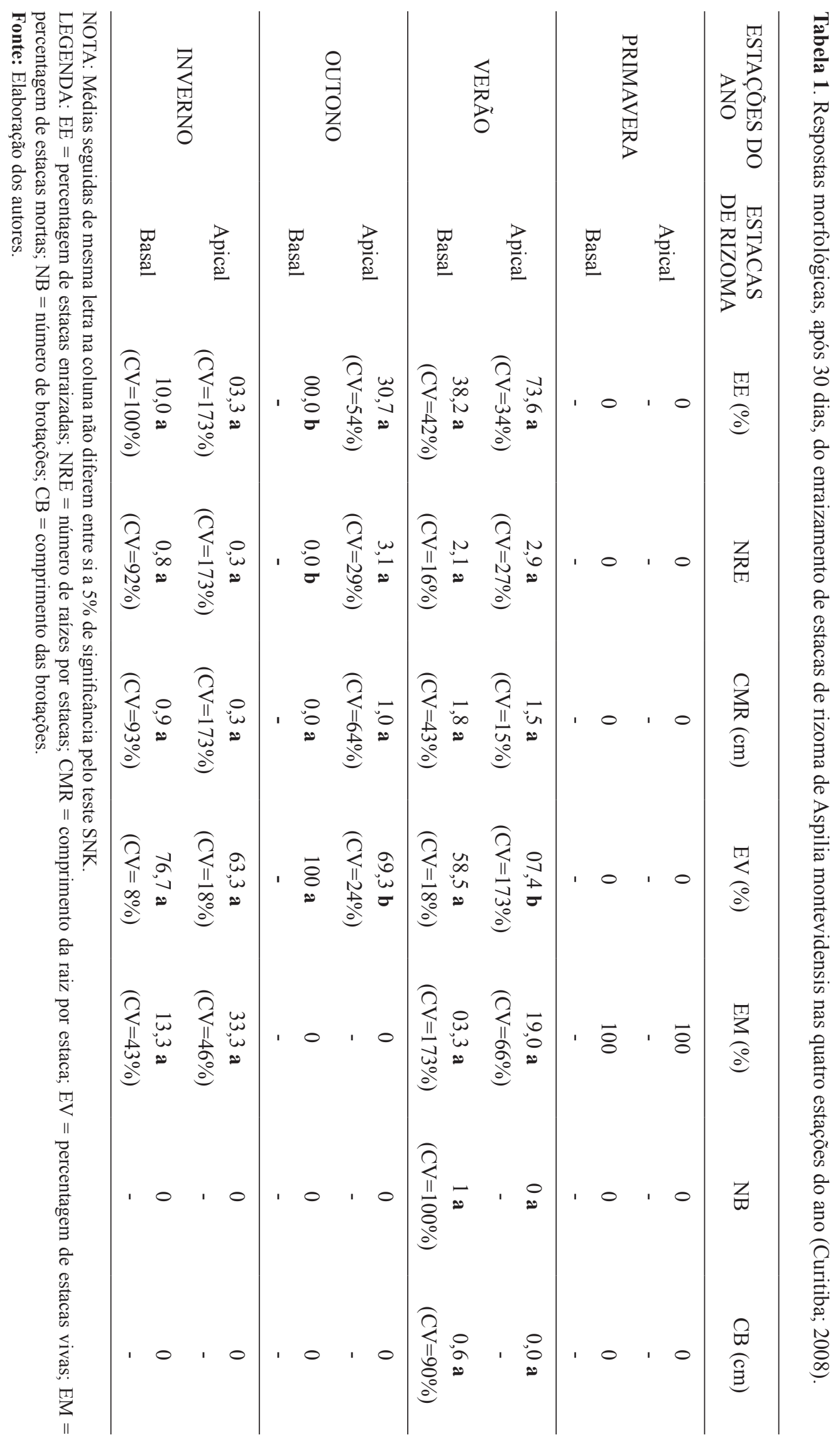


O resultado da implantação do experimento ao final da primavera se mostrou insatisfatório, nesta avaliação todas as estacas foram classificadas como mortas. Hartmann et al. (2002) afirmam que o corte de raízes durante a primavera, quando a planta mãe esta produzindo intensamente o crescimento de ramos novos, deve ser evitado.

Ao contrário do anterior, o experimento implantado no final de outono foi o único período onde nenhuma estaca foi classificada como morta. Nesta estação, a porcentagem de estacas enraizadas na secção apical do rizoma $\left(\mathrm{T}_{1}\right)$ foi $30,7 \%$, diferenciando-se estatisticamente da secção basal do rizoma $\left(\mathrm{T}_{2}=0 \%\right)$ (Figura 1A). As demais estacas não enraizadas também não apresentaram brotações em ambos os tratamentos, permanecendo vivas nesta estação.

Figura 1. A) Exemplo de uma estaca de rizoma enraizado de Aspilia montevidensis. B) Porcentagem de estacas de rizoma de Aspilia montevidensis enraizadas para a secção basal e apical em cada estação do ano.

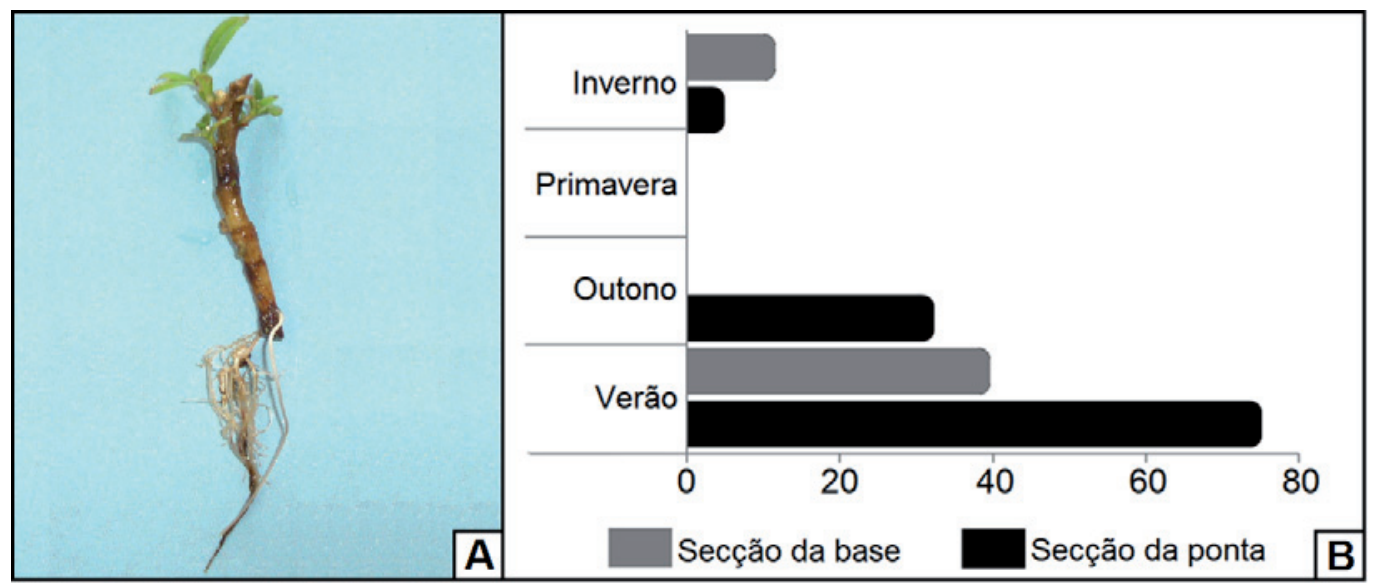

Fonte: Elaboração dos autores.

No experimento implantado ao final do inverno não foram encontradas diferenças estatísticas significativas entre os tratamentos para nenhuma variável. A porcentagem de enraizamento foi baixa, $3,3 \%$ para a secção apical do rizoma $\left(\mathrm{T}_{1}\right)$ e $10 \%$ para secção basal do rizoma $\left(\mathrm{T}_{2}\right)$. Já a porcentagem de estacas mortas foi de 33,3\% para a secção apical do rizoma $\left(\mathrm{T}_{1}\right)$ e 13,3\% para secção basal do rizoma $\left(\mathrm{T}_{2}\right)$. Este resultado contraria Hartmann et al. (2002), ao afirmarem que quando se utiliza estacas de raiz, os melhores resultados são encontrados quando estas são extraídas de plantas matrizes jovens e no final do inverno ou início da primavera, quando as raízes ainda estão repletas de carboidratos armazenados e antes do início do período de crescimento.
Durante a estação do outono e inverno, a maioria das estacas apresentaram dificuldades para enraizamentos e brotações, porém mantiveram-se vivas. Isto pode ter ocorrido devido ao período de avaliação do experimento não ter sido suficiente (30 dias) para estas estações, pois durante esse período o processo é mais lento devido à dormência causada pelas baixas temperaturas. Wendling, Paiva e Gonçalves (2005) afirmam que melhores resultados são obtidos quando as estacas são colhidas em plantas não muito velhas, na saída da estação de inverno ou começo da primavera, pois nesse período as plantas estão em repouso vegetativo e as raízes estão bem providas de reservas nutritivas. 
No verão houve diferença significativa entre os tratamentos para a variável porcentagem de estacas vivas, sendo encontrados $58,5 \%$ para a secção basal do rizoma $\left(\mathrm{T}_{2}\right)$ e 7,4\% para a secção apical do rizoma $\left(\mathrm{T}_{1}\right)$. As demais variáveis não se diferenciaram estatisticamente nesta estação, embora a porcentagem de enraizamento tenha sido bem distinta entre os tratamentos, 73,6\% para a secção apical do rizoma $\left(\mathrm{T}_{1}\right)$ e 38,2\% para a secção basal do rizoma $\left(\mathrm{T}_{2}\right)$.

Para todas as estações do ano, o surgimento de brotações mostrou-se praticamente nulo. Esta falta de brotos nas secções de rizoma também pode estar atrelada ao período de análise. No entanto, há necessidade de mais estudos, para viabilizar esse método de multiplicação. Segundo Kämpf (2005), o processo da propagação vegetativa depende da capacidade do vegetal formar novas raízes e é independente do sistema radicular oriundo da semente. O percentual de enraizamento das estacas pode ser observado na Figura 1B.

Observa-se na Figura 1B que a maiorporcentagem de estacas enraizadas ocorreu no período de verão para os dois tratamentos $\left(\mathrm{T}_{1}=73,6 \%\right.$ e $\left.\mathrm{T}_{2}=38,2 \%\right)$, mostrando-se maior na secção apical do rizoma $\left(\mathrm{T}_{1}\right)$. No outono ocorreu desenvolvimento de raízes apenas na secção apical $(30,7 \%)$. Na primavera não foi constatado enraizamento em nenhum dos tratamentos, já no inverno ambos enraizaram, porém em baixas proporções. Nesta situação ao contrário dos resultados anteriores, a secção basal apresentou maior valor $(10 \%)$. Este resultado, embora seja baixo, contraria as constatações de Luz, Carvalho e Oliveira (2011) que sugerem que a superioridade do rizoma apical, possivelmente se deve ao fato do tecido meristemático ser menos lignificado do que o rizoma mediano e basal, supondo-se que o rizoma apical tenha mais reserva nutricional e que os pontos de crescimento estejam no ápice do rizoma.

Os resultados obtidos em cada estação do ano, podem não ter sido satisfatórios devido à época de implantação do experimento, final de cada estação. Segundo Browse (1998), embora a propagação a partir de estacas radiculares possa ser bem sucedida durante a dormência, é preferível preparar as estacas na parte intermediária desse período, época em que a resposta será máxima.

Em geral, muitos dos resultados não alcançados nesta pesquisa podem estar direta ou indiretamente relacionados com o período de avaliação. Associado a este fator existe ainda a influência da característica da espécie e das estações do ano de menor atividade vegetativa (outono e inverno).

Não se obteve resultados conclusivos a respeito do potencial de enraizamento e brotação de rizoma de Aspilia montevidensis, porém constatou-se que a forma de propagação testada é mais promissora do que por sementes e estaquia caulinar.

Com base nos resultados obtidos, recomendase que em novos experimentos, seja considerado a idade, o período de preparação das estacas e avaliação do enraizamento em função das estações do ano.

\section{Referências}

BARROSO, C. M. Propagação de espécies nativas com potencial ornamental. 2006. Dissertação (Mestrado em Fitotecnia) - Universidade Federal do Rio Grande do Sul, Porto Alegre.

BIONDI, D.; LEAL, L. Potencial ornamental de espécies nativas. Revista Científica Eletrônica de Engenharia Florestal, Garça, v. 4, n. 8, 2006. Disponível em: <http:// www.revista.inf.br/florestal08/pages/ artigos/artigo09. pdf $>$. Acesso em: 13 mar. 2012.

BIONDI, D.; LEAL, L.; WENDLING, I. O uso de Aspilia setosa Griseb. no paisagismo e a sua propagação. Revista Brasileira de Horticultura Ornamental, Campinas, v. 13, p. 1472-1476, 2007. Suplemento.

BROWSE, P. M. A propagação das plantas. Tradução de Francisco Lyon de Castro. 4. ed. Lisboa: Publicações Europa-América, 1998. 228 p. (Coleção EUROAGRO. Enciclopédia de Práticas Agrícolas). 
CARVALHO, M. A. M. Variações no conteúdo e na composição de frutanos em rizóforos de Vernonia herbacea (Vell.) Rusby. 1991. Tese (Doutorado em Ciências) - Instituto de Biologia da Universidade Estadual de Campinas, Campinas.

FERRIANI, A. P.; BORTOLINI, M. F.; ZUFFELLATORIBAS, K. C.; KOEHLER, H. S. Propagação vegetativa de estaquia de azaléia arbórea (Rhododendron Thomsonii HOOK. f.). Semina: Ciências Agrárias, Londrina, v. 27, n. 1, p. 35-42, jan./mar. 2006.

HARTMANN, H. T.; KESTER, D. E.; DAVIES JUNIOR, F. T.; GENEVE, R. L. Plant propagation: principles and pratices. 7. ed. New Jersey: Prentice-Hall, 2002. 880 p.

HAYASHI, A. H. Morfo-anatomia de sistemas subterrâneos de espécies herbáceo-subarbustivas e arbóreas, enfatizando a origem das gemas caulinares. 2003. Tese (Doutorado em Biologia Vegetal) - Instituto de Biologia da Universidade Estadual de Campinas, Campinas.

HEIDEN, G.; BARBIERI, R. L.; STUMPF, E. R. T. Considerações sobre o uso de plantas ornamentais nativas. Revista Brasileira de Horticultura Ornamental, Campinas, v. 12, n. 1, p. 2-7, 2006.

INSTITUTO DE PESQUISA E PLANEJAMENTO URBANO DE CURITIBA - IPPUC. Curitiba em dados. 2010. Disponível em: <http:/www.ippuc.org.br/ Bancodedados/Curitibaemdados/Curitiba_em_dados Pesquisa.htm?ampliar $=\mathrm{n} \%$ E3o $>$. Acesso em: 06 set. 2010.
KÄMPF, A. N. Propagação. In: (Org.). Produção comercial de plantas ornamentais. 2. ed. Guaíba: Agropecuária, 2005.

KLEIN, R. M.; HATSCHBACH, G. Fitofisionomia e notas sobre a vegetação para acompanhar a planta fitogeográfica do município de Curitiba e arredores (Paraná). Boletim da Universidade do Paraná, Curitiba, v. 4, p. 1-30, 1962.

LEAL, L.; BIONDI, D.; GUIMARAES, O.; SANTOS JUNIOR, J. B. Estudos preliminares de espécies nativas para o uso no paisagismo. In: EVINCI - EVENTO DE INICIAÇÃO CIENTÍFICA, 12., 2004, Curitiba. Livro de Resumos... Curitiba: UFPR, 2004. p. 240-240.

LUZ, J. M. Q.; CARVAlhO, A. F.; OLIVEIRA, M. C. de. Estaquia de rizomas do carapiá, planta medicinal em extinção. Horticultura Brasileira, Brasília, v. 29, n. 2, abr./jun. p. 258-261, 2011.

TAKEDA, I. J. M.; FARAGO, P. V. Vegetação do parque Estadual de Vila Velha: guia de campo. Curitiba: Serzegraf, 2001. 419 p.

WENDLING, I.; PAIVA, H. N.; GONÇALVES, W. Técnicas de produção de mudas de plantas ornamentais. Viçosa, MG: Aprenda Fácil, 2005. 223 p. (Coleção jardinagem e paisagismo. Série produção de mudas ornamentais, v. 3). 
